\title{
UMA ABORDAGEM COMPREENSIVA DO INDIVIDUALISMO
}

\author{
Fabrício José Rodrigues de Lemos ${ }^{1}$ \\ Gerson Neves Pinto ${ }^{2}$
}

\begin{abstract}
Resumo
O individualismo possui inúmeras facetas - as quais vêm sendo criticadas principalmente por não se preocuparem com o coletivo, tampouco com o social. Portanto, utilizando-se do método de pesquisa bibliográfico, com base em uma dessas facetas - o individualismo ético proposto por Ronald Dworkin - o artigo busca demonstrar como, sem deixar de lado a preocupação com a liberdade individual e os princípios da igualdade, ou seja, sem que haja a descaracterização de quaisquer dos princípios individualistas, essa concepção, ainda que ligeiramente modificada - com a adição de outras concepções de bem -, pode, sem incorrer em nenhuma forma de conflito, também se preocupar com os interesses coletivos.
\end{abstract}

Palavras-chave: Individualismo. Liberdade individual. Interesse coletivo. Justiça social.

\section{INTRODUÇÃO}

Narcisismo egocêntrico alheio às preocupações coletivas? Conceito político, social e moral atento somente às liberdades individuais? Egoísmo que se desvela em pouca ou nenhuma solidariedade para com outrem? As críticas dirigidas ao individualismo são inúmeras, porém todas possuem o mesmo foco: a visualização exacerbada do indivíduo e o desinteresse da concepção para com o social. Afastando-se de concepções pejorativas, o artigo pretende identificar um tipo de individualismo dentre muitos, que, fiel às liberdades individuais e aos direitos fundamentais do indivíduo, seja também atento às preocupações da coletividade. $O$ texto então argumenta no sentido de que o individualismo ético, como proposto pelo jurista americano Ronald Dworkin, pode representar esse papel e, ao preencher essa lacuna, desembaraçar-se dessa sorte de críticas.

Portanto, antes de adentrar no mérito proposto, de início, o artigo irá tratar sobre a evolução teórica acerca do tema, de maneira a estreitar o escopo visado e fornecer subsídios para que se atribua ao individualismo

\footnotetext{
${ }^{1}$ Mestrando em Direito Público, na Linha de Pesquisa Sociedade, Novos Direitos e Transnacionalização, pela Universidade do Vale do Rio dos Sinos - Unisinos (2014). Integrante do Núcleo de Direitos Humanos da Unisinos (NDH). E-mail: fabrjr@gmail.com

${ }^{2}$ Possui doutorado na École Pratique Des Hautes Etudes - Sorbonne, Paris (2011). Foi professor na Universidade de Santa Cruz do Sul - UNISC e na PUC/RS. Atualmente, é professor adjunto da Escola de Direito da Universidade do Vale do Rio dos Sinos UNISINOS. E-mail: gerson.p@terra.com.br
} 
ético a qualidade de possível titular do papel proposto. Assim sendo, indicará, em termos amplos, com base no estudo proposto por Louis Dumont e Alain Renaut, um apanhado histórico sobre o individualismo, para que se possa ter uma visão mais focada das razões utilizadas na escolha do individualismo ético como intermediário entre as liberdades individuais e o interesse coletivo, de maneira a lançar fundamento ao que se pretende tratar na terceira parte do trabalho, qual seja, o embate entre liberdades individuais e interesses coletivos - no que se aproximam, no que se afastam.

Então, postas as considerações delineadas acima, o presente artigo projeta apreciar, através de análise mais detalhada da concepção individualista proposta por Dworkin, a demonstração de como o individualismo, tão criticado por deixar de lado o interesse coletivo em benefício do indivíduo, mostra-se, em sua face ética, em consonância com as demandas de grupo sem, entretanto, deixar de lado suas raízes de preocupação com as liberdades individuais.

Tal exame será feito, para que, ao final, instigue reflexões sobre como, atualmente, pode o individualismo coexistir com teorias e concepções atentas à proteção e garantias de direitos fundamentais coletivos.

\section{INDIVIDUALISMO}

Um dos pontos importantes da análise de Dumont é acerca da origem dos direitos individuais. Como sabemos, existe um debate sobre como se originou esta noção de um indivíduo portador de direitos. Para autores como Strauss (2009), MacIntyre (2007), isto é o resultado genuíno da imaginação dos primeiros filósofos modernos, i.e., Hobbes, Locke e Rousseau, que consideraram o homem de forma isolada, ou seja, desvinculado de sua herança histórica. Para autores como, por exemplo, Villey (2003), estes direitos individuais são fruto de uma combinação do voluntarismo teológico e do nominalismo filosófico frente ao racionalismo da filosofia moderna. Como irá sustentar Villey (1964), para Duns Scotus e Guilherme de Ockham, o direito não se coloca mais como a relação justa ${ }^{3}$ entre os homens e as coisas, como era o caso em Aristóteles e Tomás de Aquino, mas deve ser entendido, sobretudo, como liberdade e poder. E como indica Villey, o ponto de partida do sistema jurídico moderno e um de seus conceitos principais será, exatamente, o direito subjetivo.

Segundo a conhecida tese de Villey, e será exatamente esta a qual Dumont irá seguir para explicar o surgimento dos direitos individuais ${ }^{4}$, a definição do direito como o objeto da justiça, aquilo ao qual a justiça se

\footnotetext{
${ }^{3}$ Villey vai definir o direito como sendo um princípio específico: "a natureza das coisas". Mas, como justamente lembra Villey (1964, p 80), "Il n'est pas de termes plus vagues et plus ambigus que ces deux mots de nature et de chose qui ont reçu au cours des âges des acceptions si diverses". Neste sentido, como Villey sugere, temos que assinalar uma diferença relevante : a « nature des choses » clássica que corresponde a uma concepção jusnaturalista segundo a qual o "droit doit être tiré de l'observation de toute la nature et je dirait précisément de la nature des choses" (1964, p. 80) e a "nature des choses des modernes" que corresponde a uma concepção normativista segundo a qual "le droit est pourl'essentiel un produit non de la nature mais del'esprit”. (1964, p. 81).

${ }^{4}$ É o que irá afirmar Dumont (1991, p. 85): "Ce qui suit est un simple résumé de Villey, op. cit. [La Formation de la pensée juridique moderne. Le Franciscanisme et le Droit (Cours d'histoire et de philosophie du droit), Paris, Les Cours de droit, 1963] p. 147-275”.
} vol.09, n. 01, Rio de Janeiro, 2016.pp. 288-308 
dirige e aspira, havia sido transmitida sem maiores problemas do mundo clássico ao mundo medieval através da mediação da ética aristotélica e do direito romano, encontrando finalmente em Tomás de Aquino a sua melhor síntese e tradução. Mas, segundo Villey, esta tradição do direito clássico ocidental, encontrou um obstáculo, em princípio pelo nominalismo de Ockham e depois pelo racionalismo dos primeiros filósofos da modernidade. Como bem afirma Dumont (1991, p. 85), Ockham é aquele que expõe sistematicamente o nominalismo em face do realismo de Tomás de Aquino e será assim, "le fondateur du positivisme et du subjectivisme en droit, et tout ceci représente une invasion spectaculaire de l'individualisme". ${ }^{5}$ A tradição voluntarista remonta aos primórdios da filosofia ocidental: a julgar pelo que nos informam Platão e Aristóteles, os sofistas seriam uma espécie de voluntaristas, pois insistiam sobre o caráter artificial das leis da cidade, não passando de um mero consenso entre os homens. Mas, seguindo a famosa tese de Villey, o voluntarismo moderno se afirmará mais profundamente com a obra dos filósofos franciscanos Duns Scotus e Guilherme de Ockham. Deste modo, a origem dos direitos individuais (ou subjetivos) estaria, segundo esta tese (VILLEY, 1975a, p. 176 e ss; 1975b), na ideia de lei divina a vontade livre de Deus - que torna os homens livres, ou seja, delega alguns poderes ou faculdades aos homens. Será, segundo esta tese, Ockham o primeiro a definir explicitamente o direito subjetivo como poder da vontade. Depois de estudar a controvérsia entre o papado e os franciscanos sobre a doutrina da pobreza apostólica e o problema da propriedade dos bens, Ockham irá afirmar que não existe algo como "a ordem franciscana. ” A ontologia de Ockham, para citar Alain Delibera (1996, p. 389), "é uma ontologia aristotélica reduzida que somente admite seres individuais". O indivíduo é o centro, o núcleo do nominalismo de Ockham.

Os fundamentos do direito subjetivo serão extraídos do nominalismo de Ockham que tende assim a uma visão monista do mundo e transfere ao domínio do direito as formas de resolver os problemas da teologia medieval. ${ }^{6} \mathrm{O}$ direito subjetivo torna-se então autônomo e esta solução para um problema que envolvia a moralidade cristã, surpreendentemente, acaba por fundamentar o individualismo dos tempos modernos. Deste modo, dado que não existe nada ontologicamente real além do ser individual, conclui Dumont (1991, p. 88-89):

Lorsque la notion de droit s'attache, non à un ordre naturel et social, mais à l'être humain particulier, cet être humain particulier devient un individu au sens moderne du terme. [...] En général, et au plan social proprement dit, il n'y a plus de place pour lídée de communauté. Elle est supplantée par la liberté de l'individu, qu'Occam étend du plan de la vie mystique à celui de la vie en société. Implicitement au moins, nous avons quitté la communauté pour une société, et les racines religieuses de cette première transition, aussi décidée que décisive, sont évidentes?

\footnotetext{
${ }^{5}$ O fundador do positivismo e do subjetivismo no Direito, e tudo isso representa uma dramática invasão do individualismo. (DUMONT, 1991, p. 85, tradução livre do autor).

${ }^{6}$ Como podemos constatar, Michel Bastit (1997, p. 326) afirmará que a conseqüência desta ontologia de Ockham é de "rabattrel'intellect sur la volonté et finalement sur la toute puissance".

7 [...] quando se adiciona o conceito de direito, não é uma ordem natural e social, mas o ser humano em particular, este ser humano é um indivíduo em particular, no sentido moderno do termo. [...]. Em geral, no plano social particularmente dito, não há espaço para a ideia de comunidade. Ele é suplantada pela liberdade do indivíduo, que Occam estende do plano da vida mística à vida na sociedade. Pelo menos vol.09, nº. 01, Rio de Janeiro, 2016.pp. 288-308 
Há grandes dificuldades na definição do termo "individualismo", tendo em vista a infinidade de oposições distintas que lhe podem ser atribuídas: "[...] podemos interrogar-nos sobre se, vivendo da sua oposição a uma multiplicidade tão diferenciada de contrários, ele possui em si mesmo uma determinidade própria”. (RENAUT, 2000, p. 65). O filósofo francês Luc Ferry, em tentativa de conceituar o termo de maneira simples e ampla, explica que, na modernidade, a virtude passou da natureza, dos talentos naturais - cuja perspectiva implica em um mundo essencialmente não igualitário, voltado para a diferenciação hierárquica dos seres -, para a liberdade, que supõe um plano em que todos os seres se equivalem: e essa reviravolta provocou grandes consequências no pensamento filosófico-político.

Situa-se a virtude não mais na natureza, mas na liberdade, então todos os seres se equivalem, e a democracia se impõe. O individualismo é consequência desse raciocínio. Para os Antigos, o Todo, o cosmos, é infinitamente mais importante do que suas partes, do que os indivíduos que o compõem. É o que se chama de 'holismo' - que vem do grego holos, que quer dizer 'tudo'. Para os Modernos, a relação se inverte: o Todo não tem mais nada de sagrado, já que para eles não existe cosmos divino e harmonioso no seio do qual seria necessário encontrar um lugar a se inserir. Apenas o indivíduo conta, de tal modo que, a rigor, uma desordem é melhor que uma injustiça. Não se tem mais o direito de sacrificar os indivíduos para proteger o Todo, pois o Todo não é nada mais do que a soma dos indivíduos, uma construção ideal na qual cada ser humano, porque é 'um fim em si', não pode mais ser tratado como um simples meio. (FERRY, 2007, p. 156).

Alain Renaut, filósofo francês, indica que a lógica individualista é aquela da independência individual.

A lógica do individualismo, e Dumont tem razão neste ponto, é a da independência, da 'libertação dos entraves', que tem por horizonte a forma como o indivíduo moderno, como já o prefigurava o renunciante hindu, 'só se preocupa com si mesmo'. A valorização da independência ou da 'auto-suficiência', que é levada ao extremo, conduz - como o negar? - ao gesto daquele que 'abandona a vida social e as suas condicionantes' (...) 'para se consagrar ao seu progresso e destino próprios'. Ao aprofundar esta dimensão da ideologia moderna e ao explorar os seus efeitos perversos, Dumont inscreve a sua reflexão na grande tradição que Constant e Tocqueville haviam aberto: quando De la démocratie en Amérique evocava os riscos incorridos por uma sociedade onde os homens 'giram incessantemente sobre si mesmos para obterem pequenos e vulgares prazeres com que enchem a sua alma' e onde 'cada um deles, colocado à parte, é como que um estranho face a todos os outros', tratava-se já de apontar as consequências desta 'liberdade dos Modernos' que Constant definira explicitamente em termos de independência'. (RENAUT, 2000, p. 77).

O presente escrito não pretende se perder na historicidade do desenvolvimento da concepção individualista - inclusive porque, dada a amplitude da investigação e o espaço aqui disponível, tal demanda certamente restaria incompleta. Entretanto, para fins de auxiliar na melhor compreensão do termo, cuja antiga e nova forma, "estão separadas por uma transformação tão radical e tão complexa que foram precisos nada menos de dezessete séculos de história cristã para completá-la, e talvez prossiga ainda em nossos dias" (DUMONT, 1985, p. 36), o artigo trará um breve apanhado geral - e útil - de sua evolução. Para tanto, utilizará principalmente o roteiro indicado por Louis Dumont (1985, p. 35 e ss).

implicitamente, saímos da comunidade para uma sociedade, e as raízes religiosas dessa primeira transição, também pensada como decisiva, são óbvias. (DUMONT, 1985, p. 88-89). 
Nesse sentido, portanto, ao analisar o trabalho de Dumont, depreende-se que, historicamente, a evolução das relações entre a Igreja e o Estado fez emergir o "indivíduo-no-mundo". Provendo o que Dumont (1985, p. 53) chama de "resumo do mundo", o autor projeta acontecimentos-chave para a evolução das relações entre a Igreja e o Estado até a coroação de Carlos Magno, em 800: trabalha, primeiramente, com a conversão ao cristianismo pelo imperador romano Constantino no início do século IV, que pôs a questão da definição do que seria um Estado-cristão, considerando-se que, ante a atitude do imperador, a Igreja viu-se obrigada a unificar-se mais, eis que, agora, por converter-se em uma instituição oficial do Estado, estava frente a frente com o mundo.

Santo Agostinho, tendo papel importante na sedimentação do papel da Igreja como instituição oficial do Estado, pregava pela liberdade voluntária do homem, ainda que submetido à predestinação de concepção divina. "Estava posta, portanto, a diferença entre a lex aeterna (lei natural, ou lei de Deus, que se preocupa com a alma) e a lex temporalem (lei temporal, ou lei dos homens, que trata da justiça) ". (CASTILHO, 2012, p. 59). Com isso, Santo Agostinho "tirou a religião da condição de metafísica, aproximando-a da filosofia, com metodologia de estudo, e enfim transformando-a em teologia - o cristianismo deixou a clandestinidade e mudou a história do Ocidente". (CASTILHO, 2012, p. 59).

Consequentemente, ante essa nova condição, a Igreja não poderia mais "continuar a depreciar o Estado tão livremente quanto o fizera até então. [...]. O Estado tinha, em suma, dado um passo fora do mundo, na direção da Igreja, mas, ao mesmo tempo, a Igreja tornou-se mais mundana do que fora até aî". (DUMONT, 1985, p. 53). Pela primeira vez, então, afrontou-se o problema da compatibilidade entre os valores (ultramundanos) da igualdade e os da hierarquia.

Pois, com base nas colocaçoes acima, para que o individualismo moderno pudesse se desenvolver, fora necessário uma contaminação do componente individualista e universalista do cristianismo na vida mundana, "a ponto de, progressivamente, as representações se unificarem, o dualismo inicial se apagar e a vida no mundo ser concebida como podendo ser inteiramente conforme ao valor supremo" (RENAUT, 2000, p. 72): ao fim desse processo, o indivíduo-fora-do-mundo se tornara no moderno-indivíduo-no-mundo.

Ainda que Dumont (1985, p. 62) indique que há certa fraqueza em seu estudo ao interromper suas colocações no século VIII para retorná-las após a Reforma Protestante, o autor argumenta no sentido de que, com base no foco proposto, as interações entre indivíduo, Igreja e mundo se concluem em Calvino, que construiu sua tese sobre a fundamentação colocada por Lutero, indicando que "a sua Igreja é a última forma que a Igreja podia adotar sem desaparecer". (DUMONT, 1985, p. 63).

A dicotomia hierárquica que caracterizava o nosso campo de estudo chega ao fim: o elemento mundano antagônico, ao qual o individualismo devia até então reservar um lugar, desaparece inteiramente na teocracia calvinista. $\mathrm{O}$ campo está completamente unificado. $O$ indivíduo está agora no mundo, e o valor individualista reina sem restriçôes nem limitaçôes. Temos diante de nós o indivíduo-no-mundo.(DUMONT, 1985, p. 63). 
Passando à concepção política e estatal a partir do século XIII, o autor indica que, entre as sociedades modernas e aquelas consideradas antigas - ainda que esclareça que algumas sociedades modernas também o fazem -, em que o político e/ou social vêm à frente das demais necessidades, aquelas possuem como premissa a primazia dos direitos do homem individual, o que determina a natureza das boas instituições políticas. De forma a organizar uma distinção mais clara entre os tipos de sociedades, Dumont aduz que é necessário indagar-se acerca de qual é o conceito principal em que a valorização fundamental é baseada, "se é o todo, social ou político, ou o indivíduo humano elementar". (DUMONT, 1985, p. 75). Com isso, o autor leva à distinção de dois tipos de indivíduo:

1. O sujeito empírico da palavra, do pensamento, da vontade, amostra indivisível da espécie humana, tal como o observador encontra em todas as sociedades;

2. O ser moral, independente, autônomo e, assim (essencialmente), não social, tal como se encontra, sobretudo, em nossa ideologia moderna do homem e da sociedade. (DUMONT, 1985, p. 75).

Ante a distinção feita, Fabian Arzuaga (2014, p. 04) indica que a união dessas contradições - utilizando a terminologia em termos de individualismo quantitativo (ser empírico) e qualitativo (ser moral) - coloca o individualismo como uma antinomia repleta de preocupantes consequências políticas:

On the one hand, quantitative individualism breeds conformity and flattens difference. If all individuals are alike by virtue of a shared essence or disposition, then no particular individual is special, unique, or important; in their sameness, individuals share a dubious equality in that they are exchangeable, replaceable and even macabrely expendable; no particular individual is cherished if all are abstracted as identical atoms vying to live the same life in the same space. On the other hand, championing the irreducible uniqueness and concretion of individuals within qualitative individualism can lead to equally troubling political implications. These include restricting the status of individual to an elite who are thought to be uniquely able to achieve selffulfillment; the perfectibility of the individual as cultured 'exceptional individual' or 'great personalities' and even the identification of individual self-realization with "pure" national or cultural identities.8

A gênese da ideia moderna do homem e da sociedade, argumenta Dumont (1985, p. 87), é aquela fiadora da segunda concepção de indivíduo - o ser moral , em que, sob a influência do individualismo cristão e estóico, na modernidade, "aquilo a que se chama direito natural (por oposição ao direito positivo) não trata de seres sociais mas de indivíduos, ou seja, de homens que se bastam a si mesmos enquanto feitos à imagem de Deus e enquanto depositários da razão". Com isso, conclui-se que os princípios fundamentais do Estado e sociedade se extraem das próprias qualidades inerentes no homem, "considerado como um ser autônomo,

\footnotetext{
${ }^{8}$ Por um lado, o individualismo quantitativo gera conformidade e achata diferenças. Se todos os indivíduos são iguais em virtude de uma essência ou disposição compartilhadas, então nenhum indivíduo em particular é especial, único ou importante; em sua uniformidade, os indivíduos compartilham a igualdade duvidosa na medida em que podem ser trocados, substituíveis e até mesmo, de forma macabra, dispensáveis; nenhum indivíduo em particular é valorizado se todos são abstraídos como átomos idênticos que disputam viver a mesma vida no mesmo espaço. Por outro lado, defendendo a singularidade irredutível e concreção de indivíduos dentro do individualismo qualitativo pode levar a implicações políticas igualmente preocupantes. Estes incluem restringir o status de indivíduo para uma elite que se pensa ser a única capaz de alcançar a auto realização; a perfectibilidade do indivíduo como 'indivíduos excepcionais' cultos ou 'grandes personalidades' e até mesmo a identificação de auto realização individual com as identidades nacionais ou culturais 'puras'. (ARZUAGA, 2014, p. 04, tradução livre do autor).
} 
independentemente de todo e qualquer vínculo social ou político". (DUMONT, 1985, p. 87). Ainda que essa autonomia e independência do ser humano possa ser encontrada no estado de natureza, foi da dedução dos princípios da vida social e política que os juristas lançaram bases para a concepção de Estado democrático moderno.

O Estado deixou de derivar como um todo parcial da harmonia decretada por Deus do todo universal. Ele explica-se simplesmente por si mesmo. O ponto de partida da especulação já não é mais o conjunto da humanidade, mas o Estado soberano individual e autossuficiente, e esse mesmo Estado individual alicerça-se na união, ordenada pelo direito natural, de homens individuais, numa comunidade revestida do poder supremo. (GIERKE apudDUMONT, 1985, p. 87).

Nesse sentido, em que o escopo passa do conjunto da humanidade para o Estado soberano individual e autossuficiente, fundamentado na união de homens individuais ordenado pelo direito natural em uma comunidade revestida de poder supremo, se tem a oposição entre a ideia de universitas, uma unidade orgânica, homogênea, e societas, associação:

Societas (...) tem aqui o sentido limitado de associação, e evoca um contrato pelo qual os indivíduos se 'associaram' numa sociedade. Esse modo de pensar corresponde à tendência, tão divulgada nas ciências sociais modernas, que considera a sociedade como consistindo em indivíduos - indivíduos que estão em primeiro lugar em relação aos grupos ou relações que eles constituem ou 'produzem' entre si mais ou menos voluntariamente. (DUMONT, 1985, p. 88).

Para Dumont, entretanto, seria correto tratar a sociedade como universitas, 'o todo', eis que "a sociedade, com suas instituições, valores, conceitos, língua, é sociologicamente primeira em relação a seus membros particulares, que só se tornam homens pela educação e a adaptação a uma sociedade determinada”. (DUMONT, 1985, p. 88). Indica que a designação de totalidade social como 'sociedade' em oposição a universitas é herança do direito natural moderno e de seus continuadores. Ainda que haja o predomínio da noção de 'sociedade' como 'associação', Dumont indica que a palavra universitas não perdeu seu significado, eis que restava dificultosa a renúncia à denominação quando se queria levar em consideração, em sua unidade, o corpo social ou político.

De fato, a noção aprofundada de sociedade sofreu um eclipse parcial no período e na escola do pensamento em questão, como a testemunha o destino da palavra universitas. Com o predomínio do individualismo contra o holismo, o social nesse sentido foi substituído pelo jurídico, o político e, mais tarde, o econômico. (DUMONT, 1985, p.91).

Com o advento da Declaração dos Direitos do Homem e do Cidadão de 1789, a Assembleia Constituinte francesa marcou o triunfo do Indivíduo. Apesar de ter sido precedida por outras cartas de direitos, que, inclusive, a influenciaram, a declaração exerce uma ação poderosa, quase irresistível, ainda nos dias atuais, eis que "foi a primeira a ser adotada como fundamento da Constituição de uma grande nação, imposta a um monarca reticente pela manifestação popular e proposta como exemplo à Europa e ao mundo". (DUMONT, 1985, p. 109). O que se objetivou com a declaração foi justamente a retirada das bases estatais da alçada do Estado, para focá-la no consenso dos cidadãos, retirando-as do alcance da autoridade política, eis que o documento direcionava os princípios solenes que a Constituição deveria adotar. (DUMONT, 1985, p. 110). 
Como base para as garantias adotadas pela declaração, os franceses buscaram na América do Norte os preceitos que implantariam - mormente a liberdade de religião. A democracia francesa estava principalmente preocupada com a igualdade entre os homens, sendo que Tocqueville argumenta que "a Revolução Francesa foi, no fundo, um fenômeno religioso, enquanto movimento que se considerava absoluto e pretendeu refundir toda a vida humana (...)”. (DUMONT, 1985, p. 114). Tal fato se tornou evidente ao ver como os franceses, adeptos da ideia do homem como indivíduo, foram inspirados pelas ideias de direitos abstratos concebidas pelos puritanos do Novo Mundo. (DUMONT, 1985, p. 114). Portanto, consoante constatado por Dumont (1985, p. 114), "uma vez mais, a religião cristã tinha empurrado o Indivíduo para a frente".

Depois do amplo apanhado de informações históricas, em que foram deixadas de lado, propositalmente, as falas sobre Rosseau e Hobbes - as quais serão abordadas nos tópicos infra -, resta caracterizar, então, a que tipo de individualismo este artigo se remete.

\section{Qual individualismo?}

O antropólogo Louis Dumont (1991) explicita que, ao se falar em indivíduo, designam-se, simultaneamente, duas coisas: um objeto fora de nós e um valor:

De um lado, o sujeito empírico que fala, pensa e quer, ou seja, a amostra individual da espécie humana, tal como a encontramos em todas as sociedades; do outro, o ser moral independente, autônomo e, por conseguinte, essencialmente não-social, portador de nossos valores supremos, e que se encontra em primeiro lugar em nossa ideologia moderna do homem e da sociedade. (DUMONT, 1985, p. 36).

À vista disso, a diferenciação entre individualismo e holismo decorre, principalmente, do objeto a ser valorizado: no individualismo, a liberdade do indivíduo e sua primazia em relação a uma comunidade, sociedade ou em face do Estado são afirmadas; no holismo, ocorre a valorização da sociedade como conjunto. No mesmo sentido, aponta Renaut (2000, p. 68):

Dumont opõe duas grandes ideologias que lhe parecem corresponder a dois tipos de sociedades: - A ideologia holista valoriza a totalidade social e negligencia ou subordina o indivíduo humano'. A esta ideologia corresponde a sociedade hierárquica onde, como é o caso do sistema indiano das castas, a ordem resulta da 'utilização do valor' (a saber: o valor do todo), surgindo portanto as partes ou os elementos (nomeadamente os indivíduos) como subordinados ao todo ou àquilo que encarna/exprime/figura o todo. - A ideologia individualista, pelo contrário, valoriza o indivíduo, leia-se (...): 'o ser independente, autônomo', 'essencialmente não social', e correlativamente 'negligencia ou subordina a totalidade social'. A esta ideologia corresponde logicamente a sociedade igualitária visto que, se o indivíduo como tal é o valor supremo, não poderá estar submetido a ninguém senão a ele mesmo - encontrando-se, assim, qualquer princípio de hierarquia excluído em benefício do princípio da igualdade. É este individualismo que constitui 'o valor cardinal das sociedades modernas', nomeadamente no registo econômico-político onde a aplicação do princípio de igualdade toma a forma do 'liberalismo'.

Apesar de ser amplamente discutido, o tema 'individualismo' resguarda uma gama bastante diversificada de conceituações. Max Weber (2004, p. 206) aduz que “a expressão 'individualismo' abarca os elementos mais vol.09, n. 01, Rio de Janeiro, 2016.pp. 288-308 
heterogêneos que se possam conceber" - que podem ser, paradoxalmente, excludentes e/ou com viés exaustivo. Facilmente se verifica que há uma infinidade de termos com os quais o tema pode ser acoplado - são tantos os termos que Alain Renaut $(2000,65)$ põe a seguinte indagação: “[...] o individualismo é o oposto do universalismo ou do totalismo, do holismo, do altruísmo, do tradicionalismo, do socialismo ou até, segundo um neologismo recente, do societalismo?"

Pode-se até mesmo se questionar se, diante de uma grande gama de opostos, há uma possível conceituação objetiva de individualismo. No individualismo atomista, por exemplo, maior foco das críticas comunitaristas, os indivíduos são abstraídos daqueles concretos, corporificados, particulares - o ser empírico de Dumont, consoante classificado acima -, e, postos como fundamentalmente iguais e dotados dos mesmos direitos - o ser moralde Dumont -, são classificados como seres egocêntricos cujas relações sociais se limitam, sobretudo de maneira instrumental, àquelas que visam a satisfação de interesses próprios, concebidos separadamente em relação àqueles da sociedade. ${ }^{9}$ Roberto Gargarella (2008, p. 143-144) indica, nesse sentido:

$\mathrm{O}$ 'atomismo' é um termo com o qual os comunitaristas tendem a descrever aquelas doutrinas 'contratualistas', surgidas no século XVIII, que adotam uma visão da sociedade como um agregado de indivíduos orientados por objetivos individuais. $\mathrm{O}$ 'atomismo' parte de uma análise sobre os indivíduos e seus direitos, aos quais atribui uma óbvia prioridade perante as questões 'sociais'. Defender uma postura atomista, segundo os comunitaristas, implica ignorar que os indivíduos só podem crescer e se auto-realizar dentro de certo contexto particular.

Essa visão é baseada na "suggestion that it is possible to develop a complete characterization of individual psychology that is fully pre-social, then deduce what will happen when a group of individuals, so characterized, enter into interaction with one another." ${ }^{10}$

Por sua vez, o individualismo metodológico, que contrasta com o holismo metodológico, "amounts to the claim that social phenomena must be explained by showing how they result from individual actions, which in turn must be explained through reference to the intentional states that motivate the individual actors". ${ }^{11}$ Em outras palavras, é "a perspectiva de que qualquer teoria nas ciências sociais sobre grupos sociais ou instituições deve invariavelmente ser redutível a teorias sobre o ser humano individual, portanto o indivíduo se torna a base primária da investigação". (RACHELS, 2006, p. 259).

\footnotetext{
${ }^{9}$ Until recently, the 'abstract' and 'atomistic' individual was the dominant feature of the critique of liberal individualism among communitarian, Marxist, and feminist academic political theory. Abstract individuals are those abstracted from concrete, embodied, and particular individuals who are posed as fundamentally equal and are endowed with inalienable rights. Such individuals are also deemed atomistic - self-centered individuals whose only social relations with others are instrumental toward the fulfillment of their own individual desires conceived of as separate and apart from ties with others. (ARZUAGA, 2014, p. 06).

${ }^{10}$ Sugestão de que é possível desenvolver uma caracterização completa da psicologia individual totalmente pré-social, para depois deduzir o que irá ocorrer quando um grupo de indivíduos, assim caracterizado, interagir com um outro. (HEATH, 2010, tradução livre do autor).

${ }^{11}$ Equivale à reivindicação os fenômenos sociais devem ser explicados demonstrando como eles resultam de ações individuais, o que, por sua vez, devem ser explicadas por em referência ao estado de intenção que motiva os atores individuais. (HEATH, 2010, tradução livre do autor).
} 
Ademais, para fins de comparação, o individualismo moral, ainda que não presuma que o indivíduo seja egoísta, indica que o ser somente é livre quando se submete "apenas às obrigações assumidas voluntariamente; seja o que for que se deva a alguém, deve-se em virtude de algum ato de consentimento - uma escolha, uma promessa ou um acordo que se tenha feito, seja ele tácito ou explícito". (SANDEL, 2013, p. 264). Essa posição presume que a origem das obrigações do indivíduo são aquelas assumidas individualmente, não aquelas impostas pela tradição, hábito ou condição herdada. A crítica feita a esse tipo de individualismo resume-se na seguinte frase: "[...] essa visão de liberdade deixa pouca margem para a responsabilidade coletiva ou para o dever de arcar com as consequências morais das injustiças históricas perpetradas por nossos predecessores". (SANDEL, 2013, p. 264).

Consoante indica Michael Sandel (2013, p. 276-277), a crítica posta ao individualismo moral ocorre porque há três tipos de responsabilidade moral - deveres naturais, obrigações voluntárias e obrigações de solidariedade. A obrigação voluntária, como já se presume, requer do indivíduo seu consentimento. A primeira, decorrente da "vontade autônoma (Kant) ou do contrato social hipotético (Rawls)" e a última, cuja fundamentação decorre do "aspecto localizado da reflexão moral, no reconhecimento do fato de que minha história de vida está implicada na história dos demais indivíduos". (SANDEL, 2013, p. 277).

Acerca da definição de individualismo, Alain Renaut (2000, p. 104) indica:

A confusão entre individualismo e as suas formas eventualmente degradadas, a saber, o narcisismo característico, pelo menos em parte, do individualismo contemporâneo, induz uma leitura globalmente pejorativa da modernidade. Ao discernirmos melhor a natureza e os diferentes rostos do individualismo, deveríamos apercebermo-nos como, a partir do próprio seio da modernidade e sem renunciar aos seus valores, é concebível evitar as derivas do individualismo.

Por isto, no espírito destacado no excerto acima e ante essa ampla gama de interpretações representadas pelos exemplos dados acima, cumpre salientar que, ao tratar de individualismo, o presente artigo não se remete ao egoísmo, ao narcisismo, tampouco ao egocentrismo, mas sim ao individualismo ético cunhado por Ronald Dworkin (2013, p. 636), que possui dois princípios basilares na fundamentação de uma teoria de moralidade política.

O primeiro princípio afirma que é objetivamente importante que qualquer vida humana, depois de iniciada, tenha êxito, em vez de fracassar - que o potencial dessa vida se realize, em vez de desperdiçar-se -, e que isso é igual e objetivamente importante no caso de cada vida humana. Digo 'objetivamente' importante para salientar que o êxito da vida humana não é importante só para a própria pessoa ou para os que lhe são próximos. Todos temos motivo para nos preocupar com o destino de qualquer vida humana, mesmo que seja de um estranho, e de esperar que seja uma vida bem-sucedida. O segundo princípio reconhece essa importância objetiva, não obstante, insiste que essa pessoa - a pessoa em foco -, tem uma responsabilidade especial por todas as vidas, e que, devido a essa responsabilidade especial, ela tem o direito de tomar decisões fundamentais que definam, para ela, o que seria uma vida bem-sucedida.

Dworkin (2013, p. 639) explicita que a teoria da moralidade política decorrente da adoção dos dois princípios acima descritos será tanto igualitária quanto liberal: 
Esta será uma teoria igualitária, pois insistirá que o governo deve tratar a vida de cada pessoa que governa como tendo grande e igual importância, e construir suas estruturas econômicas e outras estruturas e políticas com esse princípio igualitário em mente. E também será uma teoria liberal, pois insistirá que o governo deve finalmente deixar as pessoas livres para tomar decisões que definam os parâmetros do êxito de suas próprias vidas.

Desse modo, ao assumir essa abordagem, o artigo se afasta também da concepção moderna de individualismo, em que o indivíduo valoriza "acima de tudo a independência como liberdade sem regras" (RENAUT, 2000, p. 78), expressão cunhada por Rousseau. (DUMONT, 1985, p. 101 e ss). O faz concordando com Alain Renaut, que, ao comentar sobre esse aspecto, faz a seguinte ponderação:

A independência absoluta, a pura auto-suficiência não coincidirão, com efeito, com a recusa de qualquer regra que venha limitar a 'vontade espontânea' ou 'arbitrária'? Porque aceitar regras seria, por exemplo, ter em consideração o problema das relações com o outro e das condições necessárias para a coexistência, problema esse cuja simples consideração significaria já que o indivíduo não se basta a si mesmo e pensa não ter apenas necessidade de si para existir. Da autonomia como independência desliza-se assim, através de um jogo de equivalências consideradas como óbvias, para a pura e exclusiva preocupação com o eu, narcisista e hedonista. (RENAUT, 2000, p. 78).

Destarte, buscando o "nascimento de um mundo moral no seio do qual indivíduos, pessoas, são valorizados na medida de suas capacidades de se desprenderem da lógica do egoísmo natural para construir um universo ético artificial" (FERRY, 2007, p. 156), uma vez estabelecidos os parâmetros utilizados no artigo e o tipo de individualismo adotado, passar-se-á à diferenciação entre liberdade individual e interesse coletivo.

\section{Liberdade individual versus interesse coletivo}

Nesta seção, o artigo pondera acerca da liberdade individual em oposição ao interesse coletivo. Nesse passo, levando em consideração os parâmetros estabelecidos pelo individualismo ético, buscará abordar questões relativas à existência ou não da liberdade individual e se o interesse coletivo deve predominar sobre a liberdade individual - ou vice-versa. Ademais, intentará discernir quais os critérios a se adotar para estabelecer a predominância de um sobre o outro. Porém, antes de adentrar no cerne do tema proposta para esse subcapítulo, o artigo dissertará acerca de ambas as expressões, iniciando pela primeira.

Trata-se de uma tarefa ingrata tentar obter uma conceituação satisfatória de liberdade individual: todo indivíduo tem a sua própria ideia de liberdade; poucos, porém, conseguem torná-la universal. Quando o fazem, tratam a liberdade individual em conceitos amplos - muitos doutrinadores, por exemplo, a qualificam em termos de positivo e negativo em relação à ideia de vida boa de cada ser humano. (CARTER, 2012).

A liberdade não é a liberdade de fazer o que se quer a qualquer preço, mas de fazer o que se quer respeitando os verdadeiros direitos do próximo. É preciso fundamentar a comunidade, não no obscurecimento ou na diluição da liberdade e da responsabilidade individuais, contudo no respeito compartilhado e concreto por tal liberdade e responsabilidade. (DWORKIN, 2013, p. 331). 
Entretanto, considerando que a concepção de liberdade não necessariamente precisa ser colocada em termos fechados (i.e., liberdade é...), justamente ante o fato de que cada ser humano possui uma ideia própria individual do que é liberdade, resta ao artigo que busque indicar sob quais condições alguém possui liberdade individual, sob quais condições alguém é livre para agir da melhor maneira que lhe convier, e sob quais circunstâncias o indivíduo realmente é livre. Para tanto, colaciona o excerto abaixo, em que Dworkin possui as mesmas preocupações:

Under what circumstances is someone free to act as he wishes? Is his freedom compromised only when he is subject to some external constraint - only when he is tied up or locked up, for example? Or when he is mentally ill? Or when he cannot govern himself or control his appetites as he would wish? Or when he does not behave as right reason and true morality require? Or is his freedom illusory whenever his choices and behavior are inevitable, given prior events or forces beyond his control? Is he free, that is, only if and when his own will acts as the uncaused cause of his behavior? ${ }^{12}$

Tais questões remetem-se diretamente ligadas à escolha acerca do individualismo ético, assumida no subcapítulo anterior, tendo em vista a seguinte ponderação colocada por Dworkin:

I argued that people have a foundational ethical responsibility to live well, to make something of their lives, and that living well is a matter of making appropriate decisions over one's life. But if no one is ever responsible for his decisions, the idea of living well or badly makes little sense. No decision can ever make a life better or worse lived. ${ }^{13}$

Nesse sentido, Colin Bird apresenta três princípios acerca da liberdade de cunho individualista para lidar com problemas concernentes às violações de liberdade e, também, às questões colacionadas acima, propostas por Dworkin.

Liberty is not merely 'a' good on par with others, but a special kind of good. Its uniqueness is such that it should never be sacrificed for the sake of other kinds of goods. Like all goods, no matter how special, liberty can and must occasionally be restricted for some reasons. The only justifiable reason for restricting liberty compatible with (1) is to permit liberty to be restricted 'only for the sake of liberty itself.' Principle (2) implies that liberty cannot be restricted for the sake of equality or justice. But equality and justice are fundamental political values. To reconcile liberty with equality and justice without violating liberty, we should combine liberty with them, as follows: 'Each person has an equal right to a fully adequate scheme of equal basic liberties which is compatible with a similar scheme of liberties for all. ${ }^{14}$

\footnotetext{
${ }^{12}$ Sob quais circunstâncias é alguém livre para agir como desejar? Sua liberdade é comprometida apenas quando ele está sujeito a alguma restrição externa - apenas quando ele está amarrado ou preso, por exemplo? Ou quando ele é doente mental? Ou quando ele não pode governar a si mesmo ou controlar seus apetites como ele deseja? Ou quando ele não se comporta como a razão correta e a verdadeira moralidade exige? Ou é a sua liberdade ilusória sempre que suas escolhas e comportamentos são inevitáveis, dados eventos anteriores ou forças além de seu controle? Ele está livre, isto é, apenas se e quando a sua própria vontade atua como causa não causada de seu comportamento? (DWORKIN, 2011.p. 221, tradução livre do autor).

${ }^{13}$ Argumentei que as pessoas têm uma responsabilidade ética fundacional para viver bem, para fazer algo de suas vidas, e que viver bem é uma questão de fazer as decisões adequadas sobre a própria vida. Mas se ninguém nunca é responsável por suas decisões, a ideia de viver bem ou mal faz pouco sentido. Nenhuma decisão pode fazer uma vida ser melhor ou pior vivida. (DWORKIN, 2011.p. 221, tradução livre do autor).

${ }^{14}$ Liberdade não é meramente 'um' bem em pé de igualdade com outros, mas um tipo especial de bem. Sua singularidade é tal que ele nunca deve ser sacrificado em prol de outros tipos de bem. Como todos os bens, não importa o quão especial, a liberdade pode e deve, ocasionalmente, ser restringida por algumas razões. A única razão justificável para restringir a liberdade compatível com (1) é permitir que a liberdade seja restrita 'somente em prol da própria liberdade'. Princípio (2) implica que a liberdade não pode ser restringida por causa de igualdade ou justiça. Mas a igualdade e a justiça são valores políticos fundamentais. Para conciliar liberdade com igualdade com justiça, sem vol.09, n. 01, Rio de Janeiro, 2016.pp. 288-308 
Vemos assim que o centro do debate jusfilosófico contemporâneo é o embate entre a autonomia e a comunidade, entre liberdade e solidariedade, no qual um só cresce às custas do outro: quanto mais liberal ou autônomo, menos solidariedade ou comunidade e vice-versa. A existência da comunidade se justifica principalmente na maior satisfação dos interesses dos indivíduos. O tema clássico do bem comum desapareceu por completo da agenda contemporânea.

Segundo John Finnis, ${ }^{15}$ a origem desta mudança encontra-se no início do séc. XVII, especialmente a partir do pensamento de Hobbes (1988): ao estabelecer o contraste ente a lei (lex) e os direitos (jus), o filósofo afirma que a lei é uma restrição à liberdade, justificando-a em nome da segurança:

Jus e lex, o direito e a lei, é necessário distingui-los um do outro. Pois o direito consiste na liberdade de fazer ou de omitir, ao passo que a lei determina ou obriga a uma dessas duas coisas. De modo que a lei e o direito se distinguem tanto como a obrigação e a liberdade, as quais são incompatíveis quando se referem à mesma matéria.

O direito se identifica com a liberdade individual e se contrapõe à lei, como algo anterior à lei e que está limitado por ela. Hobbes deseja sustentar que um homem possui o máximo de direitos quando se encontra no "estado de natureza", i.e., na ausência da lei, pois "numa tal condição todo homem tem direito a todas as coisas, incluindo os corpos dos outros." (HOBBES, 1988). Mais tarde, afirma Finnis ${ }^{16}$, autores como Locke e Pufendorf adotarão esta estipulação segunda a qual "um direito é paradigmaticamente uma liberdade." ${ }^{17}$

De certa forma, podemos afirmar com Finnis que estes autores, ao identificar o direito com a liberdade individual, estabelecem as bases do mais puro individualismo. Este antagonismo entre direito e lei, entre bem individual e bem comum, constitui um ponto importante do debate jusfilosófico dos dias atuais.

Talvez, para compreendermos melhor esta questão do conflito entre o bem individual e o bem comum, devamos examinar a concepção moderna de "bem" que é uma "inovação conceitual" que Hobbes protagoniza e que representa uma grande transformação para a filosofia moral. Conforme as próprias palavras de um grande comentador contemporâneo de Hobbes, Luc Foisneau (2009, p. 210), "segue-se logicamente que o 'bem’ não mais reside na 'natureza dos objetos em si', mas no juízo das pessoas que o desejam". Existe uma "mudança subjetivista na filosofia moral" em Hobbes porque agora cada homem, segundo suas sensações e sua imaginação, ou seja, segundo sua subjetividade definirá o que é bom para si. Não é mais o objeto, segundo Foisneau, o que detém ou determina o significado do bem, mas o próprio homem.

violar a liberdade, devemos combinar a liberdade com elas, como segue: 'Cada pessoa tem igual direito para um esquema totalmente adequado de liberdades básicas iguais que seja compatível com um sistema semelhante de liberdades para todos.' (BIRD apud KHAWAFA, 2000, p. 78-79, tradução livre do autor).

15 "Pushed as far as Hobbes's purpose, this contrast between law and rights deprives the notion of rights of virtually all its normative significance". (FINNIS, 1980, p. 208).

16 "Nor did Locke or Pufendorf; yet they did adopt his stipulation that 'a right' (jus) is paradigmatically a liberty". (FINNIS, 1980, p. 208).

17 "ius enim in eo positum est quod alicuius rei liberum habemus usum" ("o direito consiste no livre uso de qualquer coisa"). (LOCKE, 1954, p. 10, tradução livre do autor). 
De acordo com essa ordem de exposição, que retoma resumidamente o sistema dos Elementos de Filosofia $^{18}$, Hobbes afirma claramente que a nova filosofia moral depende da grande descoberta filosófica da modernidade, a saber, da idéia segundo a qual não conhecemos as coisas nelas mesmas, mas apenas com elas nos aparecem na percepção. Com isto, Hobbes, ao reconhecer que não importa, ou não existe mais o "bom em si", mas sim o que cada homem entende como bom para si. Nessa perspectiva, o egoísmo é uma teoria que considera ser sempre racional privilegiar a escolha que melhora a posição do próprio agente em detrimento daquelas que são suscetíveis de melhorar a situação de outrem. MacNeilly sublinha, ademais, que existe uma variante dessa teoria que ele chama de egoísmo hedonista a qual considera que a razão da escolha em favor de uma preferência reside sempre no prazer ou na dor ${ }^{19}$.

O que se identifica como sendo central neste ponto é que a concepção do bem deixou de ser objetiva para ser subjetiva na teoria da justiça de Hobbes, pois cada um vai buscar o bem como individuo, ou seja, em relação a si, de forma que o que pode ser bom para um pode não ser para o outro. Disso devemos compreender que se a perspectiva de bem para Hobbes é essa que foi exposta, a teoria da justiça hobbesiana atende dessa forma a demanda das diferentes percepções de bem, e não poderia ser diferente, uma vez que o respeito nos pactos garantirá o respeito às concepções subjetivistas de bem.

Deste modo, Hobbes reconhece a força do desejo no homem, o medo, a cobiça, o ódio, nas palavras de Hobbes (2002b, p. 58) "seja qual for o objeto do apetite ou desejo de qualquer homem, esse objeto é aquele que cada um chama bom; ao objeto de seu ódio e aversão chama mau, e ao que seu desprezo chama vil ou indigno". No Do Cidadão, Hobbes (2002a, p. 31) diz que "todo homem é desejoso do que é bom para ele, e foge do que é mau, mas acima de tudo do maior dentre os males naturais, que é a morte; e isso ele faz por um certo impulso na natureza, com tanta certeza como uma pedra cai." A visão hobbesiana é pessimista: o desejo está mais do lado da destruição dos outros do que do amor aos outros. Quanto à sociedade, seu bom funcionamento não pode ser garantido exceto por uma instancia transcendente, sempre capaz de abusar de seu poder. Para tentar pensar uma solução para este impasse, Dumont faz uma comparação entre Hobbes e Rousseau, encontrando neles uma grande similitude:

Toutes deux partent de prémisses très 'individualistes' en apparence - en accord avec les conceptions du milieu contemporain - et mènent par une stricte logique à des conclusions 'anti-individualistes'. Toutes deux sont suprêmement préoccupées d'assurer la transcendance du souverain - ici le gouvernant (ruler), là 'la volonté générale' - par rapport aux sujets, tout en soulignant lidentité du souverain et du sujet. En somme: toutes deux

\footnotetext{
${ }^{18}$ Trata-se dos Elementa Philosophiae, dos quais o De Corpore forma a sectio prima, e De Homine a sectio secunda e o De Cive a sectio tertia.

19 "It [i.e. o egoísmo hedonista] holds, with egoism, that choice is always with a view to bringing about some state of the agent which he prefers; and it adds that the preference is always for a more, rather than a less, pleasurable state." (MACNEILLY, 1968, p. 100).
} vol.09, n. 01, Rio de Janeiro, 2016.pp. 288-308 
veulent fondre dans un corps social ou politique des gens qui se pensent comme des individus. ${ }^{20}$

Dumont (1985, p. 99) compara os pontos de vista de Hobbes e Rousseau, de maneira a estabelecer um parâmetro entre a liberdade individual e o próprio individualismo: Thomas Hobbes, não sendo nem individualista nem holista, argumenta que, no estado de natureza, mesmo na ausência da Justiça, existe o poder, a honra e a língua, na qual se fundamenta a razão. Portanto, em Hobbes, temos o estado social menos alguma coisa. Essa alguma coisa é a sujeição. Ademais, outro aspecto do estado de natureza "é que as relações entre homens aí estão em correspondências exatas com o que sabemos, na realidade, das relações entre Estados, sobre os quais se diz questão sempre no estado de natureza”. (DUMONT, 1985, p. 98-99). Nesse diapasão, Dumont (1985, p. 99) argumenta que Hobbes segue Maquiavel, porém em diferente nível: "[...] a guerra dos interesses exclui toda a transcendência de normas ou de valores." O terceiro aspecto é que, mesmo no estado de natureza, o homem possui tudo o que o descreve, podendo ser qualificado por um "sistema de movimentos, de desejos e paixões, com todas as modificações e complicações introduzidas pela língua e o pensamento”. (DUMONT, 1985, p. 99). Ante esses aspectos, Hobbes separa o indivíduo em dois níveis: pré-social e social - para Dumont, o correto seria dizer pré-político e político.

Cumpre salientar que, quando Hobbes fala em sujeição, o indivíduo a que ele se refere não é aquele autossuficiente, que não existia também no estado de natureza. Desse modo, a despeito de parecer individualista, a visão de Hobbes coloca em xeque essa perspectiva, ante um enfoque direcionado ao homem dependente do Estado, "de um modo tão estreito que se identifica necessariamente, por uma parte, com o soberano". (DUMONT, 1985, p. 100).

Rousseau, por sua vez, que "estava profundamente consciente da insuficiência do individualismo puro e simples, e trabalhava no sentido de salvá-lo transcendendo-o" (DUMONT, 1985, p. 102-103), foi bastante criticado pelos liberais, por ter enxertado um rebento totalitário no âmbito democrático, face a sua afirmação absoluta de liberdade. Porém, Dumont (1985, p. 108) é categórico: "Os críticos que acusam Rousseau de ter aberto as portas às tendências autoritárias, recriminam-no, de fato, por ter reconhecido o fato fundamental da sociologia, uma verdade que, quanto a eles, preferem ignorar".

Como a vida no estado de natureza é bruta, a situação pré-social do indivíduo é solitary, poor, nasty, brutish and short. ${ }^{2 l}$ Porém, "quando obedecendo ao conselho da razão e de seu próprio desejo de conservação, esse ser entra no estado político, ele desfaz-se de uma parte de seus poderes". (DUMONT, 1985, p. 99-100).

\footnotetext{
${ }^{20}$ Ambos partem de premissas aparentemente muito 'individualistas' - de acordo com os desígnios do ambiente contemporâneo - e levam a uma conclusão lógica estritamente 'anti-individualista.' Ambos são extremamente preocupados em garantir a transcendência do soberano - aqui, o governador (governante), lá, 'a vontade geral' - em comparação com indivíduos, enfatizando a identidade do governante e o sujeito. Em suma: ambos querem misturar-se em um corpo social ou político de pessoas que pensam em si mesmos como indivíduos. (DUMONT, 1991, p. 113, tradução livre do autor).

${ }^{21}$ Solitária, pobre, sórdida, embrutecida e curta. (HOBBES apud DUMONT, 1985, p.99, tradução livre do autor). vol.09, nº. 01, Rio de Janeiro, 2016.pp. 288-308 
Desfazendo-se de seus poderes, o indivíduo é capaz de desenvolver-se em um espaço seguro, confortável, porém ao preço de sua sujeição. Ao adentrar no espaço social, o indivíduo sujeita ao povo, e "o povo é soberano e, uma vez reunidos os seus membros, reina uma estranha alquimia. Da vontade individual de todos surge uma vontade geral, que é algo qualitativamente diferente da vontade de todos e possui propriedades extraordinárias". (DUMONT, 1985, p. 104).

Por isso, "a teoria de Hobbes é representativa, absolutista e insiste na sujeição. A de Rousseau é coletiva, nomocrática e insiste na liberdade". (DUMONT, 1985, p. 101). Porém, ambas as teorias "querem fundir num corpo social ou político pessoas que se pensam como indivíduos”. (DUMONT, 1985, p. 102). Desse modo, portanto, Rousseau possuía como principal preocupação a liberdade: "ele percebia em si mesmo o indivíduo como ideal moral e reivindicação política irreprimível, o homem como ser social". (DUMONT, 1985, p. 108).

Por outro lado, ao falar em direitos coletivos, Roberto Gargarella (2008, p. 180) indica que a mera alegação de interesse por parte de um indivíduo não é suficiente para que se busque satisfazer o todo, demandando o bem coletivo a ser perseguido.

Por um lado, deparamos com um bem (não só público, mas) coletivo (um bem que surge a partir do fato de os indivíduos fazerem parte de determinado grupo); mas, além disso, e fundamentalmente, acontece que nenhum dos membros específicos desse grupo pode alegar seu próprio interesse como base para pleitear a satisfação do bem coletivo em jogo.

Especifica o autor que, seguindo o pensamento de Joseph Raz, pode-se, destarte, "um liberal defender a ideia de direitos coletivos" (GARGARELLA, 2008, p. 170), em que a coletividade suplanta o interesse de um indivíduo, sem o impedir de perseguir sua própria ideia de vida boa - no instante em que sua ideia se torna a ideia da coletividade, passa-se a tratá-la como um interesse ou direito coletivo ${ }^{22}$. Will Kymlicka (1996), nesse mesmo diapasão, defende a ideia de que é possível haver um reconhecimento e uma acomodação positiva das diferenças entre grupos por meio da asserção de "direitos diferenciados em função do grupo" (group-differentiated rights). Alguns desses direitos diferenciados em função do grupo são concedidos a indivíduos pertencentes às minorias, como, por exemplo, nos casos em que um ou mais indivíduos recebem, em virtude de sua religião, algum tipo de concessão para o descumprimento de preceito legal geralmente aplicado a todos ou então nos casos em que se garantem um currículo bilíngue nas escolas, de maneira a acomodar as diversas minorias étnicas em uma determinada região, como é o caso da população francófona no Canadá, na região de Québec. Desse modo, "é possível defender direitos diferenciados em favor de minorias nacionais de modo coerente com a defesa de princípios liberais básicos - como os princípios liberais em favor da igualdade”. (GARGARELLA, 2008, p. 171). De fato, indica Gargarella (2008, p. 171), Kymlicka assume que os princípios liberais necessitam do estabelecimento de direitos especiais para as minorias.

22 Nesse sentido, verJONES, 2008. 
Nesse mesmo sentido, há um bem-fundamentada tradição do pensamento político, vinculada a Alexis de Tocqueville e ao pluralismo inglês, que percebe a existência de grupos como algo essencial à difusão do poder e da manutenção da liberdade dentro das sociedades modernas. "According to that tradition, groups do not glower threateningly at individuals. Rather, the rights of groups help to counter and hold in check a potentially overmighty state". 23

Muitas vezes, portanto, o benefício do interesse coletivo ocorre em detrimento da liberdade individual, o que leva à indagação acerca se pode haver uma coexistência ou complementaridade entre um e outra. Joseph Raz indica que, frequentemente, os direitos e interesses perseguidos pelos grupos serão os mesmos que os indivíduos buscarão solitariamente ao criticamente "expose the error of supposing that an antagonism towards collective considerations is somehow built into the very idea or purpose of individual rights." ${ }^{24}$

Nesse passo, cumpre colacionar o contraponto feito por Irfan Khawafa acerca das visões deontológica e pragmatista sobre liberdade, em que o valor dado ao bem é ora subjetivo, ora intrínseco. Ao final, o autor pondera sobre qual seria a melhor forma de pensar o bem liberdade e acerca de quando, se alguma vez, este bem pode ser violado em benefício de outro bem.

\begin{abstract}
Liberty is an important good because it protects individuals from being violated by force. But how important is it? At one (deontological) extreme, a theorist might argue that the requirements of liberty are unequivocally and absolutely inviolable: to paraphrase Kant, 'liberty must be upheld though the heavens may fall.' On a deontic view, then, liberty's value is intrinsic, no other value can ever override it for any reason in any context. At the other (pragmatist) extreme, a theorist (or politician) might assert that liberty can unhesitatingly be traded for virtually any other good at any time: to paraphrase Mussolini, "liberty may be violated that the trains may run on time'. On a pragmatist view, by contrast, liberty's value is subjective; any value can override it for virtually any reason in any context. Obviously, neither Kantian deontology nor fascist pragmatism are defensible conceptions of liberty. The defensible conception, one would think, is to be found in the mean between them. But what is that mean? What principles govern the conditions under which liberty is to operate? When, if ever, can we violate liberty for values higher than it, and when, if ever, must we insist on its inviolability by forgoing what we might otherwise obtain? 25
\end{abstract}

\footnotetext{
${ }^{23}$ De acordo com essa tradição, grupos não olham ameaçadoramente aos indivíduos. Ao contrário, os direitos de grupos ajudam a conter e a manter em xeque um Estado potencialmente poderoso demais. (JONES, 2008, tradução livre do autor).

${ }^{24}$ Expor o erro ao supor que um antagonismo contra as considerações coletivas é, de alguma forma, acoplado à ideia ou ao propósito dos direitos individuais. (JONES, 2008, tradução livre do autor).

${ }^{25}$ A liberdade é um bem importante, pois protege os indivíduos de serem violados pela força. Mas quão importante é? Em um (deontológico) extremo, um teórico poderia argumentar que os requisitos da liberdade são inequívoca e absolutamente invioláveis: parafraseando Kant, 'liberdade deve ser apoiada, ainda que os céus possam cair'. Em uma visão deôntica, então, o valor da liberdade é intrínseco; nenhum outro valor pode substituí-lo por qualquer motivo, em qualquer contexto. No outro (pragmatista) extremo, um teórico (ou político) pode afirmar que a liberdade pode, sem hesitação, ser trocada por praticamente qualquer outro bem em qualquer momento: parafraseando Mussolini, ‘a liberdade pode ser violada para que os trens possam rodar pontualmente’. Em uma visão pragmatista, por outro lado, o valor da liberdade é subjetivo; qualquer valor pode substituí-lo por praticamente qualquer razão em qualquer contexto. Obviamente, nem a deontologia kantiana nem o pragmatismo fascista são defensáveis concepções de liberdade. A concepção defensável, alguém poderia pensar, pode ser encontrado no equilibrio entre eles. Mas o que é que isso significa? Quais princípios regem as condições em que a liberdade deve operar? Quando, se alguma vez, podemos violar a liberdade por valores mais importantes do que ela, e quando, se alguma vez, devemos insistir em sua inviolabilidade ao renunciar o que de outra forma poderíamos obter? (KHAWAFA, 2000, p. 78, grifos do autor, tradução livre do autor).
} 
Destarte, feito o contraponto entre liberdade individual e interesse coletivo, passar-se-á à conclusão, na qual, além da recapitulação do visto no artigo, se buscará, com base na argumentação despendida nesta seção, identificar em quais momentos um bem pode suplantar o outro.

\section{CONCLUSÃO}

O objetivo do presente artigo, consoante já especificado na introdução, refere-se à possibilidade de se pensar um individualismo atento, por mais paradoxal que isso possa parecer, aos interesses da coletividade. Desse modo, obedecendo a este objetivo, iniciou-se o artigo com uma pequena introdução histórica, na qual foram apresentados, a título de exemplificação, alguns tipos de individualismo - justamente aqueles considerados clássicos e já ultrapassados, como, por exemplo, o individualismo atomista -, mormente para justificar e fundamentar a escolha pelo individualismo ético proposto por Dworkin. Tal escolha se deu porque somente dessa forma se poderia defender, dados os princípios estabelecidos pelo doutrinador americano, principalmente aquele no sentido de que cada indivíduo deve se preocupar com a vida de outros como se sua fosse, um tipo de individualismo que, sem perder de vista os preceitos individualistas de liberdade, também se preocupasse com as demandas coletivas.

Logo após, ponderou-se, brevemente, acerca da liberdade individual e dos interesses coletivos, buscando conceituar, apesar das óbvias dificuldades, cada um deles, para tratar acerca do interesse coletivo como forma de limitação das liberdades individuais e de como não há conflito, mas sim complementação entre os dois bens.

Portanto, com esse viés, considerando o objetivo proposto nas primeiras linhas deste artigo, buscou-se trazer à discussão o embate entre liberdades individuais e interesses coletivos sob o ponto de vista do individualismo ético, cujos preceitos permitem, consoante visto, uma coexistência pacífica entre os dois bens sem que haja perda substancial dos princípios libertários e de igualdade.

Destarte, buscando responder às questões colocadas no artigo, a liberdade individual, de acordo com a argumentação supra, pode ser, portanto, limitada de acordo com os preceitos estabelecidos por Colin Bird. Tais princípios indicam uma liberdade que pode ser limitada apenas em confronto com a própria liberdade, mas não em benefício da igualdade ou justiça. Nesse sentido, o autor concebe, de maneira a reconciliar liberdade com outros bens, um sistema em que todos possuem direito a um esquema amplo de liberdades compatível com um sistema similar de liberdades para a coletividade.

Assim sendo, mesclando tais preceitos com aqueles propostos por Ronald Dworkin ao dissertar sobre o individualismo ético, os quais indicam uma preocupação tanto com a vida própria quanto com a vida de toda a coletividade, e aqueles apresentados por Will Kymlicka ao falar em direitos diferenciados em razão de grupo, os quais permitem uma diferenciação no tratamento daqueles indivíduos que, em função de seu grupo, se veem em 
situação de vulnerabilidade, se tem um sistema em que a liberdade individual e os interesses coletivos estão totalmente protegidos. Tal aproximação, mormente deste ponto de vista, faz com que seja possível haver uma concepção ética que, atenta à raiz do pensamento individualista, também se preocupa com o interesse coletivo sem que haja conflito entre os bens protegidos.

\title{
A COMPREHENSIVE APPROACH OF INDIVIDUALISM
}

\begin{abstract}
Individualism has many facets - which have been criticized mainly for not worrying about the collective, nor with the social. Therefore, using the bibliographic research method, based on one of these facets - the ethical individualism proposed by Ronald Dworkin - the paper demonstrates how, without leaving aside the concern for individual freedom and the principles of equality, that is, without any distortion of the individualistic principles, this view, although slightly modified - with the addition of other views of good - can, without incurring in any form of conflict, also worries with the collective interest.
\end{abstract}

Keywords: Individualism. Individual liberty. Collective interest. Social justice.

\section{REFERÊNCIAS BIBLIOGRÁFICAS}

ARZUAGA, Fabian. Political theory and the contradictions of individualism: towards a critical social theory of individualism in modernity. Trabalho não publicado apresentado no Workshop de Teoria Política da Universidade de Chicago/EUA em 10 fev. 2014. Disponível em: <http://ptw.uchicago.edu/Arzuagal4.pdf〉. Acesso em: 10 jan. 2015.

BASTIT, Michel. Les principes des choses en ontologie médiévale: Thomas d'Aquin, Scot, Occam. Bordeaux: Bière, 1997.

CARTER, Ian. Positive and negative liberty. In: STANFORD Encyclopedia of Philosophy. Monday-Friday, Mar 05 2012. Disponível em: <http://plato.stanford.edu/entries/liberty-positive-negative/>. Acesso em: 13 jan. 2015.

CASTILHO, Ricardo. Filosofia do Direito. São Paulo: Saraiva, 2012.

DELIBERA, Alain. La querelle des universaux: de platon à la fin du Moyen Age. Paris: Éditions du Seuil, 1996.

DUMONT, Louis. Essais sur l'individualisme: une perspective anthropologique sur l'idéologie moderne. Paris: Seuil, 1991.

O individualismo: uma perspectiva antropológica da ideologia moderna. Rio de Janeiro: Rocco, 1985.

DWORKIN, Ronald. Justice for hedgehogs. Cambridge: The Belknap Press of Harvard University Press, 2011. Virtude soberana: a teoria e a prática da igualdade. São Paulo: WMFMartins Fontes, 2013.

FERRY, Luc. Aprender a viver: filosofia para os novos tempos. Rio de Janeiro: Objetiva, 2007. 
FINNIS, John. Natural law and natural rights. Oxford: Clarendon Press, 1980.

FOISNEAU, Luc. Pluralismo e concepção do bem em Thomas Hobbes. In: BARRETO-LISBOA, W. STORCK, A. (Org.). Normal, moralidade e interpretação. Porto Alegre: Linus, 2009. p. 205-222.

GARGARELLA, Roberto. As teorias da justiça depois de Rawls: um breve manual de filosofia política. WMFMartins Fontes: São Paulo, 2008.

HEATH, Joseph. Methodological individualism. In: STANFORD Encyclopedia of Philosophy. Monday-Friday, Nov 16 2010. Disponível em: <http://plato.stanford.edu/entries/methodological-individualism/>. Acesso em: 02 jan. 2015.

HOBBES, Thomas. Do Cidadão. Tradução, Apresentação e Notas Renato Janine Ribeiro. 3. ed. São Paulo: Martins Fontes, 2002a.

Leviatã ou matéria, forma e poder de um estado eclesístico e civil. São Paulo: Martin Claret, 2002b. 1988.

Leviatã. Tradução de João Paulo Monteiro e Maria Beatriz Nizza da Silva. São Paulo: Nova Cultural,

JONES, Peter. Group rights. In: STANFORD Encyclopedia of Philosophy. Monday-Friday, Sep 222008. Disponível em: <http://tinyurl.com/oftuzcy>. Acesso em: 17 jan. 2015.

KHAWAFA, Irfan. Whose liberalism? Which individualism? Reason Papers. [S.1], 25, p. 73-99, 2000. Disponível em: <http://tinyurl.com/le8za2t $>$. Acesso em: 13 jan. 2015.

KYMLICKA, Will. Ciudadanía multicultural. Madri: Paidós Estado y Sociedad, 1996.

LOCKE, John. Essays on the Law of Nature (1663). Oxford: W. von Leyden, 1954.

MACINTYRE, Alasdair. After virtue: a study in moral theory. Notre Dame: University of Notre Dame Press, 2007.

MACNEILLY, Frederick S. The Anathomy Leviathan. New York: St. Martin's Press, 1968.

RACHELS, James. Os elementos de filosofia da moral. Barueri: Manole, 2006.

RENAUT, Alain. A era do indivíduo: contributo para uma história da subjectividade. Lisboa: Instituto Piaget, 2000.

SANDEL, Michael. Justiça: o que é fazer a coisa certa? Rio de Janeiro: Civilização Brasileira, 2013.

STRAUSS, Leo. Direito natural e história. Lisboa: Edições 70, 2009.

VILLEY, Michel. La formation de la pensée juridique moderne. Paris: Daloz, 1975a. 2003.

La formation de la pensée juridique moderne: cours d'histoire de la philosophie du droit. Paris: PUF,

La nature des choses dans 1'histoire de la Philosophie du Droit. Annales de la Faculté de Droit de Toulouse, Tome XII, 2, 1964, p. 69-90.

Philosophie du Droit. Paris: Daloz, $1975 b$. 
WEBER, Max. A ética protestante e o espírito do capitalismo. Companhia das Letras: São Paulo, 2004.

Trabalho enviado em 28 de julho de 2015.

Aceito em 18 de outubro de 2015. 